\title{
Research on the influence of accounting computerization and networking on E-commerce
}

\author{
Wenquan $\mathrm{Shi}^{1,2^{*}}$
}

*Correspondence:
jianfeiwu@163.com
${ }^{1}$ Faculty of Economics
and Management,
Suzhou Polytechnic
Institute of Agriculture,
Suzhou 215008, China
Full list of author information
is available at the end of the
article

*Correspondence: and Management, Suzhou Polytechnic Suzhou 215008, China Full list of author information article

\begin{abstract}
E-commerce has broken through the pattern and boundary of traditional commodity exchange, so that there is no need for face-to-face transactions between merchants and consumers. This has impacted the traditional accounting industry, which broke the environmental setting of traditional accounting industry. This requires the extension and expansion of the economic environment of the new accounting industry, which has led to the computerization of accounting and the network of further upgrades. Accounting computerization and networking have greatly improved the speed and accuracy of accounting information processing, and at the same time made the classification of accounting duties more clear. However, accounting computerization and higher-level networking have in turn affected the development of e-commerce. Due to the rapid development of e-commerce, the corresponding internal auditing schemes of traditional enterprises have been unable to meet accounting and computerization. The impact of this will constrain the further development of e-commerce. Accounting computerization and networking the internal audit of e-commerce is mainly reflected in clues, internal control, and content and environment issues. This paper analyses the impact of accounting computerization and networking on the internal auditing of e-commerce, and finally analyse the auditing setup and experience based on a company $\mathrm{H}$ in the accounting information system, and explore the accounting calculation. In the context of globalization and networking, the strategy of how to deal with the trial and control part of e-commerce.
\end{abstract}

Keywords: Accounting major, Computerization, Networking, E-commerce, Internal auditing

\section{Introduction}

Compared with the traditional accounting environment, the rapid development of e-commerce directly affects the transformation of the accounting industry's economic environment. Accounting computerization and higher-level networking are gradually being promoted and developed. Accounting computerization and networking have led to a series of profound changes in the division of accounting work, division of responsibility, review relationship and document management. The corresponding division of duties is also clearer and clearer. At the same time, the development of accounting

(c) The Author(s) 2021. This article is licensed under a Creative Commons Attribution 4.0 International License, which permits use, sharing, adaptation, distribution and reproduction in any medium or format, as long as you give appropriate credit to the original author(s) and the source, provide a link to the Creative Commons licence, and indicate if changes were made. The images or other third party material in this article are included in the article's Creative Commons licence, unless indicated otherwise in a credit line to the material. If material is not included in the article's Creative Commons licence and your intended use is not permitted by statutory regulation or exceeds the permitted use, you will need to obtain permission directly from the copyright holder. To view a copy of this licence, visit http://creativecommons. org/licenses/by/4.0/. 
computerization and networking also counters the development and transformation of e-commerce, which has brought a huge impact on the internal audit control of e-commerce [1]. In computerization and networked accounting, all data and documents are stored in related computer storage media, and the corresponding data and files are collected and summarized in the Internet environment. Traditional enterprises internal auditing has been unable to meet the security, effectiveness, and timeliness of accounting data under the computerized accounting and networking of e-commerce. In addition, the paper-based bookkeeping system used in the traditional internal auditing of enterprises has lost its role in the development of e-commerce. Instead, it is the processing flow cantered on accounting data documents [2]. However, accounting computerization and networking itself are fragile, and there is also a hidden risk to the development of e-commerce, such as computer systems being invaded by viruses, computer systems or software failures, and human error in modern e-commerce. Internal auditing has brought many difficulties, and it has also increased the risk and intensity of auditing. In summary, while accounting computerization and networking promote the development of e-commerce, it also has a huge impact and impact on the key audit control part of e-commerce, which also promotes the e-commerce review. The development of computerization and networking [3].

The internal auditing of enterprises is extremely important for traditional enterprises and emerging e-commerce, and it has a complete auditing procedure. It mainly finds out the problems existing within the enterprise through inspection and evaluation inside the enterprise, and points out that its weak links are improved, so that the whole enterprise can further improve the economic benefits [4]. There are two main aspects of internal audit of an enterprise [5]. One is the internal control system, and the other is the internal accounting control system. The development of accounting computerization and networking has a profound impact on its internal accounting control system [6].

At present, the concept of internal auditing of e-commerce under computerized accounting and networking, related classification and internal auditing methods are still unclear. Most internal control measures and auditing schemes deviate from reality [7]. Therefore, in the context of accounting computerization and networking, it is important to enhance the understanding of internal control in the new situation for e-commerce internal control staff, and to strengthen its research on connotation and technology. In addition, this work is also studying current accounting power. A key issue in the impact of accounting and networking on e-commerce [8].

There are many papers on the internalization of accounting computerization and networking for e-commerce, but most of the articles are general. It does not give a realistic coping strategy, and its guidance to practice is not enough. This article will conduct detailed analysis and discussion based on the case of a company $\mathrm{H}$, and propose corresponding solutions and suggestions [9].

\section{Methods}

\subsection{Accounting computerization and networking and internal auditing in e-commerce}

In the context of e-commerce economy, the accounting business flow chart is shown in Fig. 1. 


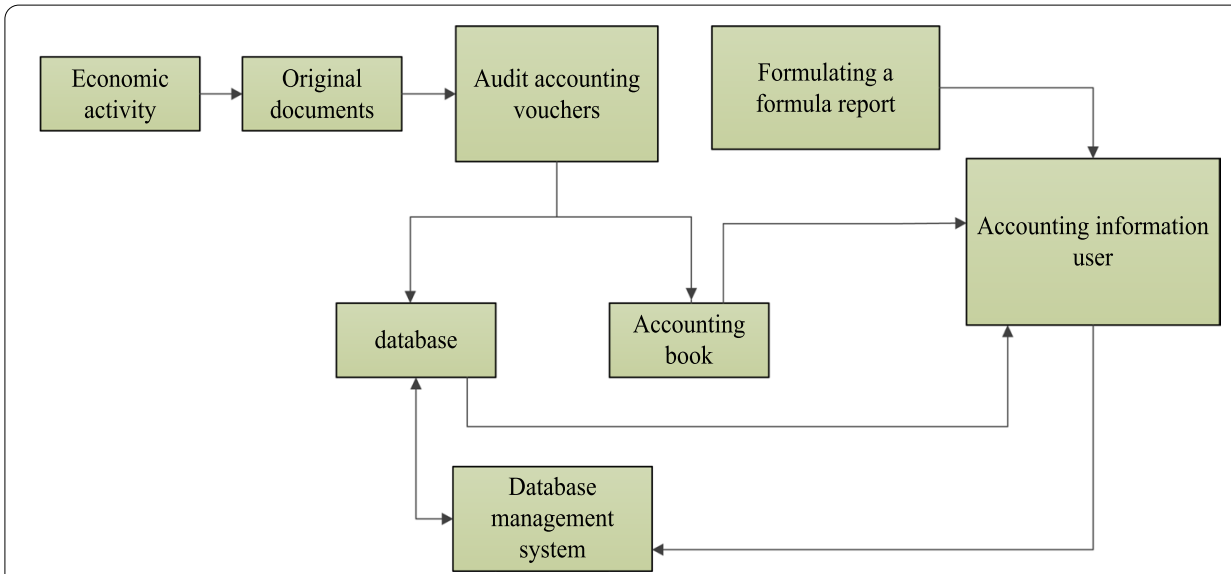

Fig. 1 The accounting business flow chart

Accounting computerization and networking are the products of the rapid development of e-commerce. Compared with the traditional accounting system, it has the advantages of high efficiency and low labour cost. China's accounting computerization and networking have developed rapidly [10].

At present, many large-scale financial and software companies in China use different languages in the design of accounting computerization and networked systems, and there is no corresponding normative operation in software compilation [10]. There is still no specification on the infrastructure.

In the background of accounting computerization and networking in China, many financial software companies do not consider the use of dedicated interfaces in the auditing interface of financial software, which makes the trial and control personnel have certain difficulties in the collection of accounting data. Therefore, strengthening the coordination and standardization of relevant interfaces is the only way for the development of accounting computerization and networking [11].

This paper discusses the detailed computerization of assets and liabilities in accounting computerization. The calculation formula of the money fund is formula 1 :

$$
\text { QM("1001", month) + QM("1002", month) + QM("1012", month) }
$$

Then the corresponding account receivable is calculated as Eq. 2:

$$
\text { QM("1122", month) }
$$

The corresponding other accounts receivable are formula 3:

$$
\text { QM("1221", month) }
$$

Then the calculation formula of the inventory is as shown in Eq. 4:

$$
\text { QM("1403", month) + QM("1405", month) + QM("5001", month) }
$$

The formula for calculating the fixed assets can be as shown in Eq. 5:

$$
\text { QM("1601", month) }
$$


The asset depreciation calculation formula is shown in Eq. 6 .

$$
\text { QM("1602", month) }
$$

Then the formula for calculating the net value of the fixed assets is as shown in Eq. 7, which is equal to Eq. 6 minus Eq. 5 [12].

$$
\text { net asset value }=\text { Fixed assets }- \text { Depreciable assets }
$$

Then the corresponding assets are totaled as the sum of all the above formulas.

The development trend of accounting computerization and networking in China is mainly divided into the following three stages:

1. In the 1990s, China proposed the development characteristics of financial software as "accounting" and "management", abandoning the original financial software with financial accounting as the core idea, and pointed out that financial software should be an integrated ERP system. It contains information technology and management ideas [13].

2. When China joined the WTO, a large number of foreign companies flooded into China, and different companies used different financial accounting software, which caused a series of conflicts. In order to solve this problem, a self-service accounting system was born, so different. Enterprises can collect, process and analyze accounting data according to their own needs [14].

3. In the new era, the rapid development of e-commerce has enabled enterprises to move financial accounting information from the original closed type to the open type. At this time, the accounting information needs to be timely and accurate, and at the same time ensure the safety and reliability of the entire accounting system [15].

Internal auditing is an indispensable means for effective management of e-commerce. It mainly consists of two parts: internal management control system and internal accounting control system. The internal auditing of e-commerce refers to the internal control, and on the basis of reviewing the internal auditing degree of the audited entity, it decides to review the content, scope and related procedures of the accounting materials, and based on this, it conforms to the normative and substantive An audit method for testing. Internal auditing has greatly reduced the risk of auditing, and has also improved the quality of auditing and audit effectiveness [16]. Its main content is five aspects: internal containment system, accounting control system, responsibility control system, property voucher management system and control system of each circulatory system in business.

There are three specific methods for internal control of e-commerce: questionnaire method, flow chart method and written explanation method [17].

\subsection{Analysis of the impact of accounting computerization on the internal control of E-commerce}

Accounting computerization and networking bring new challenges and opportunities to the internal audit of e-commerce. The computerized internalization of e-commerce internalization and control is an important subject to be studied under the new 
accounting economic environment. Controlled computerization has accumulated experience for the development and operation of financial audits of various financial software's in the later stage at a lower economic cost [18].

Compared with the goal of e-commerce internal control, accounting computerization and networking have not changed its essence, but it has changed its collection method in the collection of trial leads, and at the same time it has expanded its technological advantages. The actual scope of trial and control has made the internal auditing of e-commerce enterprises play a greater role. According to the financial software of different enterprises, the application basis of e-commerce review and control computerization network is formed [19]. Because it is often based on a specific enterprise, its implementation is relatively difficult, and the corresponding computerized development The cost is also low. At the same time, the development process of computerization based on accounting computerization network conditions can also accumulate development experience for the development of other general-purpose financial audit software for e-commerce. In summary, the impact of accounting computerization and networking on internal auditing in e-commerce can be summarized as follows:

\subsubsection{Transformation of e-commerce internal audit technology methods}

The relevant software for the audit is mandatory when conducting the audit. Before the computerization of accounting computerization appeared, the routine internal auditing of enterprises was done manually, and it was audited by a special auditor. The emergence of computerized accounting and networking has made it necessary for auditors to master computer-related knowledge and operational skills, make full use of the computer's auxiliary functions to improve the efficiency of trial and control, and accumulate experience in continuous learning, while combining the actual needs of the enterprise. The situation is further developed to develop audit software that is rigorously rigorous and has sufficient retention and audit trail capabilities. Related software such as ERP software, etc., so that in the internal audit of e-commerce, any record will be able to see its changes, deletions, etc., so that the auditors are very clear about the record of each place., thus providing clues and efficiency for the audit work.

\subsubsection{Changes in the content of internal auditing of e-commerce}

The computerized computerization and the security and reliability of the networked system are the important content and focus of the internal control of e-commerce. The biggest benefit of computerized accounting and networking is that it can greatly reduce the problem of human error caused by human error, but it also brings certain risks. Auditors are overly convinced or rely on computer systems, and when computer systems fail or audit If the personnel maliciously tamper with the audit data, the consequences will be unimaginable. Therefore, under the condition of computerized accounting and network, e-commerce internal auditors need to spend more time and energy to audit the internal control under accounting computerization and network. At the same time, in addition to the above work, auditors also need to conduct audit work based on the system in advance and in the event. 


\subsubsection{The impact of internal audit trails in e-commerce}

In the context of computerized accounting and networking, the visible cues of the trial and control part of e-commerce will be significantly reduced. The accounting data will be stored in the computer system under the computerized network, and the corresponding data generation and information transmission forms have also changed. The auditors are basically unable to track the responsible accounting business with the naked eye, while the traditional Safeguards regarding the security, reliability, integrity and accuracy of accounting data files are also not applicable. In order to audit the accounting computerization system more effectively and reliably, the relevant accounting examiners need to continuously raise the requirements and improvements in the development process of the whole system, and at the same time, the audit data and documents should be printed and saved.

\subsubsection{The impact of e-commerce internal auditors}

The rapid development of accounting computerization and networking requires e-commerce internal auditors to master computer technology in a timely and efficient manner. The accounting economic environment generated by accounting computerization and networked system is very complicated, and its corresponding internal control is relatively complicated. Internal personnel cannot rely on simple basic knowledge and original skill reserve to calculate accounting. In addition to the need to strengthen the accounting of accounting knowledge, it is also necessary to master the necessary computer knowledge and skills. At the same time, in e-commerce enterprises, it is also necessary to deal with accounting computerization and network. The technical needs of the company, cultivate the corresponding professional talents, and establish the computerized control system of the enterprise.

Based on the above influences and analysis, this paper summarizes the following problems existing in the current e-commerce internal control.

1. There are unrealized or unreasonable measures for review and control.

2. There are no trial and control measures that need to be questioned.

3. The process of internal auditing is cumbersome and cumbersome and inefficient.

\section{Experiment}

In order to further explore the impact of accounting computerization and network on the trial and control of e-commerce, this paper takes $\mathrm{H}$ company as an example to discuss its design and control, and gives corresponding countermeasures. In this paper, H Company is an electronic component manufacturer with a registered capital of 10 million US dollars. At the same time, its shareholding component is half of that of China and foreign countries. Since its establishment, it has maintained its turnover growth, but its original extensive economy has been unable to meet the new economic situation, its main problems are: extensive cost control, serious inventory backlog, and serious disconnection between the corresponding functional departments. 
After careful study of H's business, it is found that the key to H's business chain lies in sales, which is based on sales until the entire production is completed and the project acceptance is qualified. The flow chart of its business is shown in Fig. 2.

Based on the above process, in order to standardize the situation in which the salesperson violates the company's requirements or even harms the company's interests in pursuit of sales in the sales process, the following process is formulated according to the above characteristics (Fig. 3):

Based on the financial status of Company $\mathrm{H}$, the corresponding project budget and annual budget form are shown in Table 1 .

In terms of procurement management, material management mainly includes: material demand planning, material procurement, inventory management, invoice confirmation, and material valuation. The relationship between the corresponding material management module and other business modules is shown in Fig. 4.

After analyzing the project management module of $\mathrm{H}$ Company as the core module of the whole company, its main content is to control and manage the objectives of the project, and at the same time supervise and control the long-term and complex projects. In the project management module, the objectives of the project must be accurately described and the project activities can be hierarchically structured. According to the actual management characteristics of Company $\mathrm{H}$, the relationship between project and sales order and production management is as shown in Fig. 5 below:

It can be seen from the above diagram that each sales order will operate independently as a project, and then each project will be decomposed into two parts according to different properties, and the materials can be subdivided into imported materials and local materials. The service can be further decomposed into activities such as on-site supervision, preliminary acceptance, and final acceptance, thus realizing the financial management mode for the project.

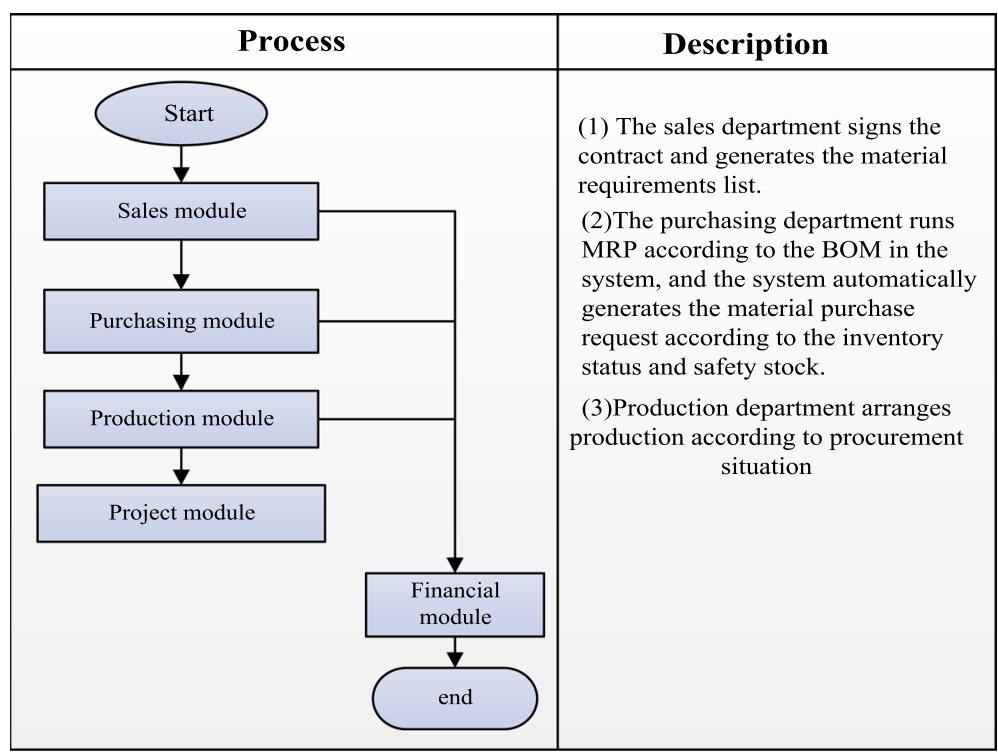

Fig. 2 Business module diagram 


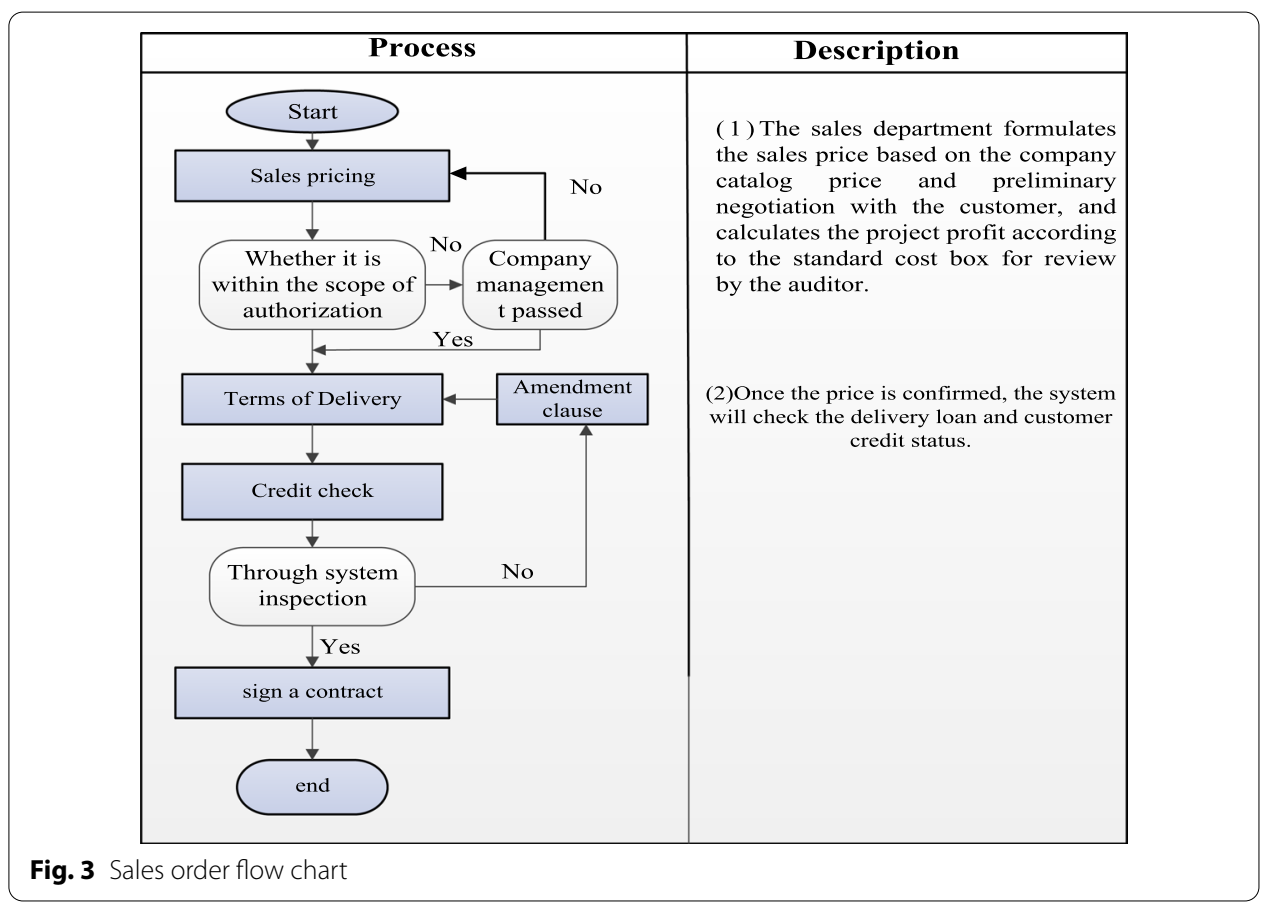

Table.1 Relationship between project budget and annual budget

\begin{tabular}{|c|c|c|c|c|c|}
\hline \multicolumn{6}{|l|}{ Project number } \\
\hline \multicolumn{6}{|c|}{ Total budget:30,000 } \\
\hline Material budget & 14,000 & Labor cost & 8000 & Other service & 1000 \\
\hline Imported materials & 13,000 & Installation supervision & 5000 & Installation training & 1100 \\
\hline Local material & 2000 & Debugging & 1100 & Delivery training & 900 \\
\hline
\end{tabular}

At this stage, $\mathrm{H}$ company's internal auditing work should pay attention to the following two aspects when dealing with the trend of accounting computerization and networking:

1. Evaluate the system user and operator authority control;

2. Evaluation of organization and management;

3. Evaluation of system maintenance control;

4. Evaluate the system operating environment;

5. Evaluation of system input and output control;

6. Evaluation of system storage;

Based on the above analysis and research on the internal control audit of $\mathrm{H}$ company, this paper gives the project flow chart of H company, as shown in Fig. 6:

The corresponding data flow diagram is shown in Fig. 7, The financial system of Company $\mathrm{H}$ is closely linked with other sub-modules, which constitutes a flow chart for internal auditing of accounting. 

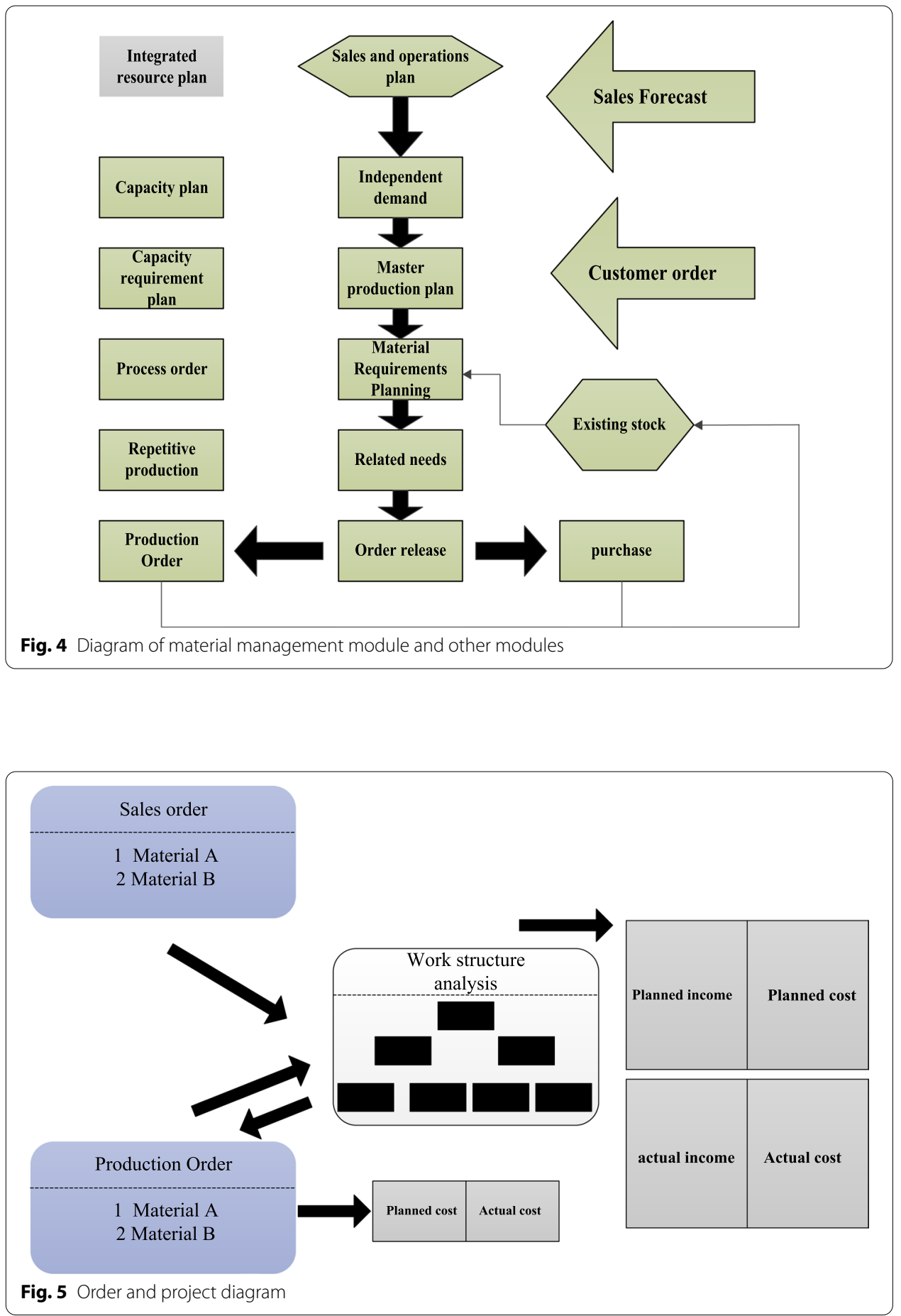

\section{Accounting and risk management strategies in E-commerce}

In order to adapt to the impact of accounting computerization and networking on the review. The internal auditing part of e-commerce is mainly processed by computer software. The rapid development and iteration of related network auditing software is one of the countermeasures. 

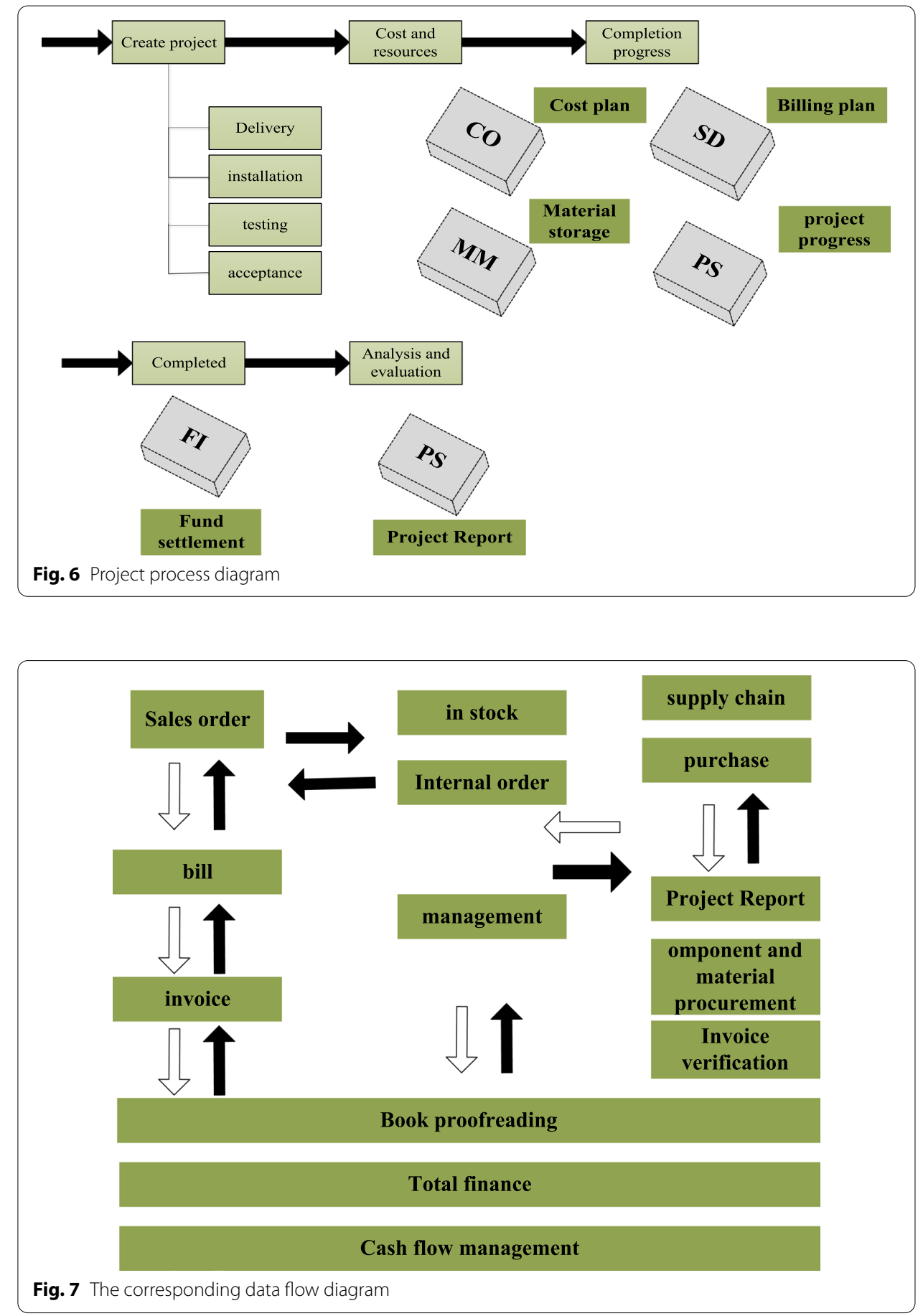

Vigorously develop the network economy, focusing on the actual part that can produce benefits, and gradually covering the audit network from the eastern coastal to the economically underdeveloped areas.

Strengthen the inspection of organizational structure, authority and the distribution and division of responsibilities, and strive to make the division of responsibilities can provide strong support for internal control. Designers should be clear about whether 
they have security regulations for computer hardware, computer programs, data files, data transfers, and data input and output.

After internal auditors verify, the corresponding technicians need to confirm further, making internal auditing more convincing and safe. Internal audit should be closely integrated with the internal control of the enterprise, and at the same time be closely integrated with economic benefits to help enterprises improve their efficiency. Pay attention to cooperation with external auditors. Strengthen the training of the professional quality of internal auditors, and at the same time standardize the internal audit system and pay attention to the knowledge update of internal auditors. The internal audit department shall formulate specifications for the enterprise financial software from the perspective of auditing, and uniformly perform registration processing, and at the same time, back up the software and report it to the audit department for record.

In the external environment, it is necessary to further strengthen the construction of e-commerce review and control. The specific content strategies are summarized as follows:

At present, China's relevant laws cannot meet the needs of the auditing part of e-commerce. Therefore, it is necessary to strengthen the intensity and progress of the network auditing legislation. Effective legislation can make people have rules to follow when conducting network auditing. Security audit refers to the audit of the computer network environment and its related activities by the auditors and the evaluation activities. Computer networks enable accounting information to be transmitted to the rest of the world via the Internet, so its security and confidentiality are greatly threatened. Modern audits must actively carry out security audit activities and at the same time take it as one of the central contents of the audit.

Because modern financial reports will greatly increase the future information of enterprises, such information must have corresponding quality assurance. In this regard, a large number of consulting CPAs are required. In the information society, intangible assets such as knowledge, information and other important information are also very important, and in the future development, the proportion of intangible assets will increase greatly, which also leads to the focus of auditing gradually on intangible assets.

\section{Results and discussion}

E-commerce has broken through the pattern and boundary of traditional commodity exchange, so that there is no need for face-to-face transactions between merchants and consumers. This has impacted the traditional accounting industry, which broke the environmental setting of traditional accounting industry. This paper analyses and discusses the impact of accounting computerization and network on the internal auditing part of e-commerce. At the same time, based on the case of $\mathrm{H}$ company, it analyses and analyses the internal auditing. Design, and finally put forward a countermeasure based on e-commerce review and control under the background of accounting computerization and network. On the whole, this paper has made effective attempts in the combination of theory and practice, and also put forward a practical and effective strategy to deal with risks. 


\section{Authors' contributions}

WS is responsible for the data collection and thesis writing of the paper.

\section{Funding \\ None.}

\section{Availability of data and materials}

Data sharing not applicable to this article as no datasets are generated or analyzed during the current study.

\section{Declarations}

\section{Ethical approval}

This article does not contain any studies with human participants or animals performed by any of the authors. All authors agree to submit this version and claim that no part of this manuscript has been published or submitted elsewhere.

\section{Competing interests}

All authors declares that he has no conflict of interest.

\section{Author details}

${ }^{1}$ Faculty of Economics and Management, Suzhou Polytechnic Institute of Agriculture, Suzhou 215008, China. ${ }^{2}$ University of the Cordilleras, 2600 Baguio, Philippines.

Received: 31 October 2020 Accepted: 24 June 2021

Published online: 09 July 2021

\section{References}

1. Y.L. Rong, Analysis about accounting computerization and network. Appl. Mech. Mater. 644-650, 6246-6249 (2014)

2. G.J. Downey, Memory practices in the sciences (review). J. Interdiscip. History 38, 553-576 (2007)

3. L.F. Gunter, S.C. Turner, Computerization in the US ornamental nursery industry. Agribusiness $\mathbf{9}(1), 77-90$ (2010)

4. B. Mathew, A. Unnikrishnan, T. Chakraborty, et al. Mining Twitter conversations around E-commerce promotional events. pp. 345-348 (2018).

5. C. Avgerou, K. Mcgrath, Power, rationality, and the art of living through socio-technical change. Mis Q. 31(2), 295-315 (2007)

6. D. Gefen, E-commerce: the role of familiarity and trust. Omega 28(6), 725-737 (2000)

7. W.H. DeLone, E.R. McLean, Measuring e-commerce success: applying the DeLone and McLean information systems success model. Int. J. Electronic Commerce $\mathbf{9}(1), 31-47$ (2004)

8. Z. Huang, W. Chung, H. Chen, A graph model for E-commerce recommender systems. J. Assoc. Inf. Sci. Technol. 55(3), 259-274 (2004)

9. Z. Huang, M. Benyoucef, From e-commerce to social commerce: a close look at design features. Electronic Commerce Res. Appl. 12(4), 246-259 (2013)

10. E. Turban, J. Outland, D. King, et al. E-commerce security and fraud issues and protections. pp. 459-520 (2018).

11. M. Choshin, A. Ghaffari, An investigation of the impact of effective factors on the success of e-commerce in smalland medium-sized companies. Comput. Hum. Behav. 66, 67-74 (2017)

12. W. Hasselbring, G. Steinacker. Microservice architectures for scalability, agility and reliability in E-commerce. in IEEE International Conference on Software Architecture Workshops. IEEE, pp. 243-246 (2017).

13. B. Guo, H. Wang, Z. Yu, et al. Detecting spammers in E-commerce website via spectrum features of user relation graph. in International Conference on Advanced Cloud and Big Data. IEEE, pp. 324-330 (2017).

14. A. Kawa, Supply Chains of Cross-Border E-Commerce. Advanced Topics in Intelligent Information and Database Systems (Springer, Berlin, 2017), pp. 173-183

15. C. Robinson, Disclosure of personal data in ecommerce: a cross-national comparison of Estonia and the United States. Telematics Inf. 34(2), 569-582 (2017)

16. L. Jiang, M. Jun, Z. Yang, Customer-perceived value and loyalty: how do key service quality dimensions matter in the context of B2C e-commerce? Serv. Bus. 10(2), 1-17 (2016)

17. Y. Fan, J. Ju, M. Xiao, Reputation premium and reputation management: evidence from the largest e-commerce platform in China. Int. J. Ind. Organ. 46(6), 63-76 (2016)

18. L. Lerche, D. Jannach, M. Ludewig. On the value of reminders within E-commerce recommendations. pp. 27-35 (2016).

19. L. Lerche, D. Jannach, M. Ludewig. On the value of reminders within E-commerce recommendations. in Conference on User Modeling Adaptation and Personalization. ACM, pp. 27-35 (2016).

\section{Publisher's Note}

Springer Nature remains neutral with regard to jurisdictional claims in published maps and institutional affiliations. 